\title{
CONTRIBUIÇÃO AO ESTUDO DE BRACHIACANTHADINI (COLEOPTERA, COCCINELLIDAE, HYPERASPINAE) ${ }^{1}$
}

\author{
Julianne Milléo ${ }^{2}$ \\ Lúcia M. de Almeida ${ }^{2}$ \\ Iracilda M.M. Lima ${ }^{3}$
}

\begin{abstract}
CONTRIBUTION TO THE STUDY OF BRACHIACANTHADINI (COLEOPTERA, COCCINELlidAE, HYPERASPINAE). Some species of Cyra are described and illustrations of pertinent characters are provided. New combinations of species is done. A key to four species of Cyra are added.

KEY WORDS. Coccinellidae, Hyperaspinae, Cyra, Hinda, Taxonomy.
\end{abstract}

Mulsant (1850) criou Cyra como uma seção dentro do gênero Cleothera. CROTCH (1874) sinonimizou Cleothera em Hyperaspis onde comenta que as espécies da seção Cyra são peculiares da América do Sul. Todos os autores subsequentes consideraram válido apenas o gênero Hyperaspis. CHAPIN (1966) revalidou o gênero Cyra em Hyperaspini na subfamília Scymninae. DUVERGER (1989) criou a subfamília Hyperaspinae e as tribos Hyperaspini e Brachiacanthadini, esta última incluindo os gêneros Brachyacantha Chevrolat, 1849, Cyra Mulsant, 1850 e Hinda Mulsant, 1850, todos com representantes Neárticos.

Com base no estudo do material-tipo do Natural History Museum, Londres (BMNH) e da University Museum of Zoology, Cambridge (UMZC), analisou-se um grupo de espécies descritas como Hyperaspis com padrão de coloração amarelada com máculas marrons e que na verdade pertencem ao gênero Cyra. Além destas, uma das espécies descritas no gênero Hyperaspis com esse padrão de máculas apresenta a tíbia anterior serrilhada, característica do gênero Hinda.

O material estudado é proveniente das seguintes Instituições: Coleção Entomológica Pe. J. S. Moure, do Departamento de Zoologia, Universidade Federal do Paraná (DZUP); Museu de Zoologia, Universidade de São Paulo (MZSP); Museu Nacional, Universidade Federal do Rio de Janeiro (MNRJ), Museu Anchieta, Porto Alegre (MAPA), além das duas estrangeiras citadas acima.

1) Contribuição número 981 do Departamento de Zoologia, Universidade Federal do Paraná.

2) Departamento de Zoologia, Universidade Federal do Paraná. Caixa Postal 19020, 81531-990 Curitiba, Paraná, Brasil.

3) Museu de História Natural, Universidade Federal de Alagoas. Rua Aristeu de Andrade 452 , 57021-090 Maceió, Alagoas, Brasil. 
O estudo morfológico evidenciou caracteres, principalmente máculas elitrais, estrutura da tíbia anterior, antena, peças bucais e genitálias masculina e feminina, que nos fornecem dados suficientes para o reconhecimento de quatro espécies de Cyra e uma de Hinda. Os dois gêneros e as espécies de Cyra podem ser facilmente separadas através de chave de identificação.

\section{Chave de identificação para dois gêneros de Brachiacanthadini}

1. Corpo em vista lateral com escavação evidente da epipleura para recepção do fêmur (Fig. 2); antenas com 11 artículos, penúltimo quadrangular e o último afilado (Fig. 3); mandíbulas robustas com forte cavidade na face externa (Fig. 4); tíbia anterior com margem externa serreada (Fig. 5); abdome com linha pós-coxal arredondada, curta (Fig. 6) ............... Hinda

2. Corpo em vista lateral com leve escavação da epipleura para recepção do fêmur

(Fig. 11); antenas com 11 artículos, o penúltimo trapezoidal e o último afilado (Fig. 12); mandíbulas robustas com leve cavidade na face externa (Fig. 13); tíbia anterior com margem externa lisa (Fig. 14); abdome com linha pós-coxal arredondada, longa, dirigindo-se para base (Fig. 15) ..... Cyra

\section{Hinda uncinata (Mulsant, 1853), comb.n. Figs 1-9}

Cleothera uncinata Mulsant, 1853: 206 (descrição).

Hyperaspis uncinata: Crotch, 1874: 219 (sistemática). - Korschefsky, 1932: 198 (catálogo). Blackwelder, 1945: 448 (catálogo). - Gordon, 1987: 27 (catálogo).

Diagnose. Corpo ovalar convexo. Tegumento amarelo-pálido com máculas marrom escuras no pronoto e élitros (Fig. 1). Pronoto com quatro máculas: duas basais unidas no centro e duas apicais triangulares. Cada élitro com quatro máculas: duas basais, a próxima da sutura mais longa e subretangular; paralela a esta uma mácula alongada sobre o calo umeral; a terceira grande, oblíqua, ocupando a metade posterior do élitro; a quarta alongada, paralela a terceira e acompanhando a margem elitral, abaixo da segunda. Sutura elitral com faixa estreita, da mesma cor das máculas, estendendo-se desde o escutelo até o ápice do élitro.

Medidas em milímetros. Comprimento 3,00-3,25. Largura 2,00-2,42.

Genitália. Machos: lobo médio assimétrico, menor que os parâmeros, base muito larga, ápice arredondado; parâmeros foliáceos, alargados no ápice, de bordos arredondados com cerdas longas (Fig. 7). Sifão alongado, curvado; ápice enrugado (Fig. 8). Fêmeas: placa genital larga, com pequeno estilo; espermateca cilíndrica, em arco com corno arredondado e ramo pouco evidente. Último esternito com densa fileira de cerdas alongadas no bordo apical (Fig. 9).

Variações intraespecíficas. As máculas do pronoto podem estar todas unidas formando dois " $\mathrm{C}$ " com as hastes voltadas para o centro. Cada élitro pode conter cinco máculas, ou seja, a terceira mácula pode estar dividida, ficando uma em forma de vírgula pequena e a outra arredondada no centro das demais máculas.

Material-tipo. O lectótipo de Hyperaspis uncinata, de Santa Catarina, Brasil, designado por GORDON (1987), foi examinado e encontra-se depositado na UMZC. 

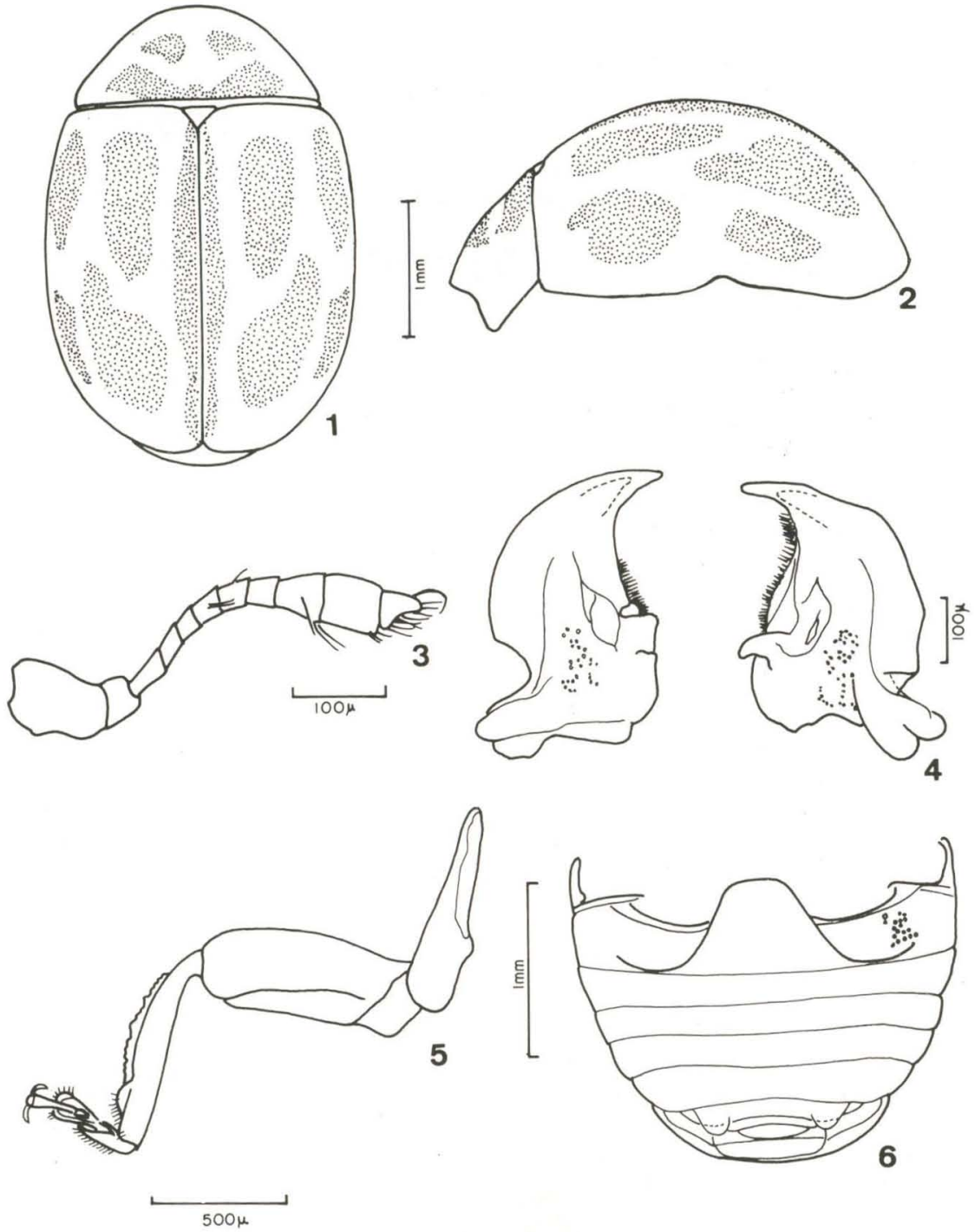

Figs 1-6. Hinda uncinata. (1) Pronoto e élitros, vista dorsal; (2) pronoto e élitros, vista lateral; (3) antena; (4) mandibulas esquerda e direita; (5) perna anterior; (6) abdome.

Material examinado. BrasiL, Minas Gerais: Camanducaia (Vila Monte Verde), 15.XI.1965, J. Halik leg., um exemplar (MZSP); Santa Bárbara (Serra do Caraça), 23-25.XI.1960, Araújo \& Martins leg., dois exemplares (MZSP); XI.1961, Kloss, Lenko, Martins \& Silva leg., um exemplar (MZSP); III.1963, U. Martins, F. Werner \& L. Silva leg., dois exemplares (MZSP); São Paulo: Atibaia, 11.XII.1971, J. Halik leg., um exemplar (MZSP); Caraguatatuba (Reserva Florestal), 2.IV.1962, Martins, Reichardt \& Silva leg., um exemplar (MZSP); Salesópolis (Estação Biológica Boracéia), 1.II.1961, K. Lenko leg., um exemplar (MZSP); Paraná: Curitiba, 


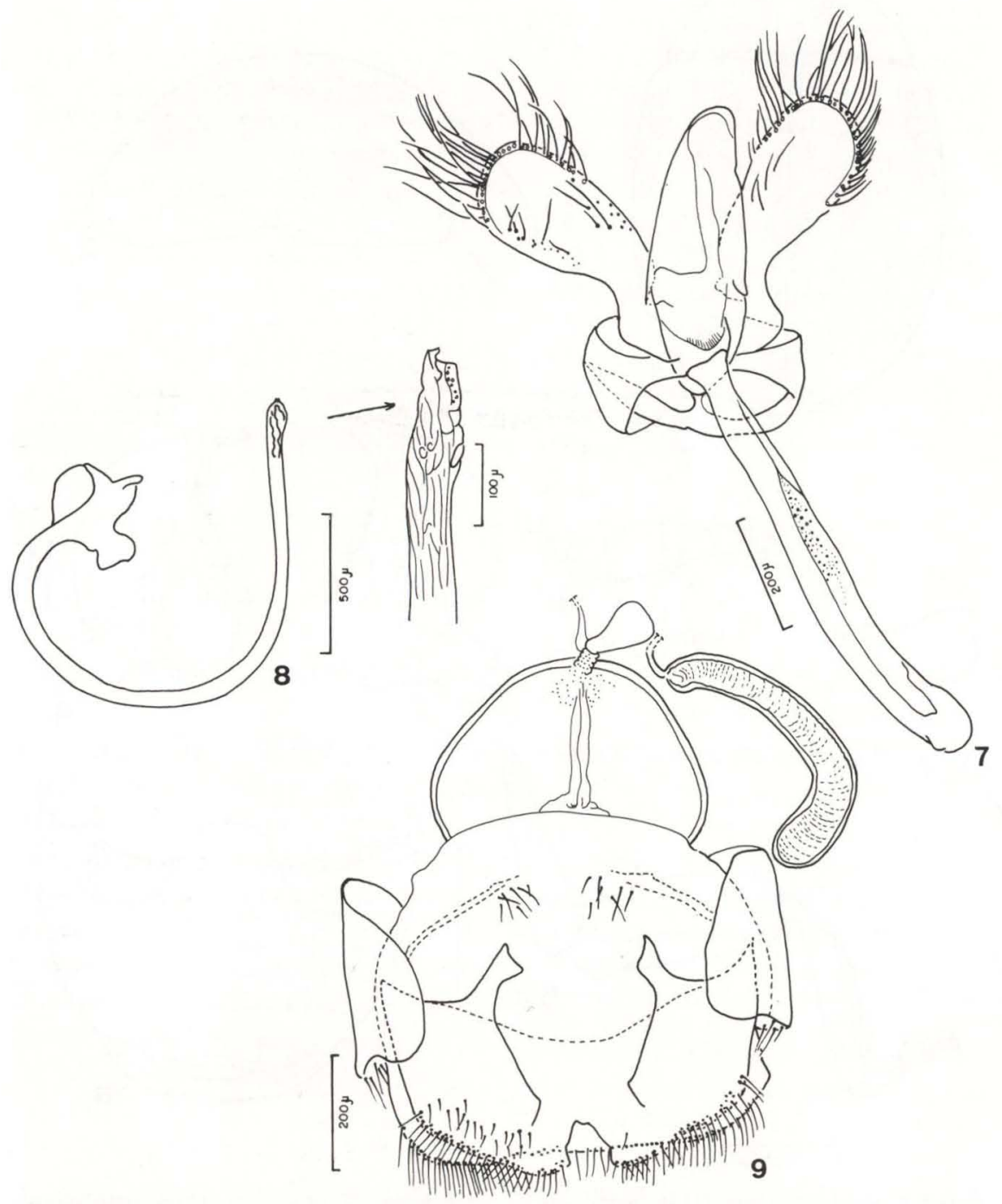

Figs 7-9. Hinda uncinata. (7) Tégmem; (8) sifão; (9) genitália da fêmea.

XI.1938, Colégio Claretiano, Pe. Moure leg., um exemplar (MNRJ); Morretes (Serra da Prata), três exemplares, ex-coleção F. Justus (DZUP); Pedreira(?), um exemplar, ex-coleção F. Justus (DZUP); Tijucas do Sul (Vossoroca), 28.XI.1975, Pe. Moure leg., seis exemplares (DZUP); Santa Catarina: Lectótipo, um exemplar (UMZC), Garuva, 4.XI.1965, Pe. Moure leg., dois exemplares (DZUP); Seara (Nova Teutônia), 15.IV.1935, um exemplar (DZUP); IX.1938, um exemplar (DZUP); 21.XII.1938, dois exemplares (DZUP); 24.VIII.1939, um exemplar 
(DZUP); 193?, 17 exemplares (MNRJ); 29.VI.1945, três exemplares (DZUP); XI.1951, um exemplar (DZUP); X.1961, três exemplares (DZUP); X.1965, um exemplar (DZUP); IV.1966, 16 exemplares (DZUP); V.1966, quatro exemplares (DZUP); IX.1966, 11 exemplares (DZUP); 21.XI.1966, dois exemplares (DZUP); 4.V.1967, um exemplar (DZUP); 11.IV.1967, cinco exemplares (DZUP); 5. IX.1967, um exemplar (DZUP); 18.II.1969, um exemplar(DZUP); 26.XI.1969, três exemplares (DZUP); 20.VIII.1971, um exemplar (DZUP); 30.XI.1971, um exemplar (DZUP); 21.XII.1971, um exemplar (DZUP); um exemplar (MNRJ); lâmina FCC 938, F. Plaumann leg., dois exemplares (MNRJ).

\section{Chave para identificação das espécies de Cyra com padrão de coloração amarela e máculas marrons}

1. Cada élitro com nove máculas; máculas pequenas não alongadas; mácula sutural afilada na porção mediana ....................... glyphica

- Cada élitro com menos de oito máculas; máculas alongadas; mácula sutural não afilada na porção mediana . ....................... 2

2. Máculas elitrais afiladas; mais de três máculas na primeira metade elitral; mácula sutural interrompida ...................... fuscomaculata

- Máculas elitrais largas; duas ou três máculas nas primeiras e segundas metades elitrais; mácula sutural inteira . . . . . . . . . . . . . . . . . 3

3. Cada élitro com sete máculas todas isoladas; mácula basal triangular; mácula do calo estreita e curta; mácula sutural iniciando-se logo abaixo do escutelo . . hybridula

- Cada élitro com sete máculas, podendo as terceira e quarta estarem unidas na base; máculas basais alongadas, retangulares; mácula do calo estreita e longa; mácula sutural iniciando-se no terço posterior elitral ........... ceciliae

\section{Cyra ceciliae (Crotch, 1874), comb.n.}

Figs 10-18

Hyperaspis ceciliae Crotch, 1874: 218 (descrição). - Korschefsky, 1932: 186 (catálogo). - Blackwelder, 1945: 446 (catálogo). - Gordon, 1987: 27 (catálogo).

Diagnose. Corpo ovalar, convexo. Tegumento amarelo-pálido, com máculas marrom-claro à marrom-escuro, no pronoto e élitros, e região próxima a linha sutural castanho-avermelhada (Figs 10-11). Pronoto com duas máculas alongadas e afiladas, laterais marrom-claro, apicais; região central com mácula em forma de V e duas máculas basais, triangulares marrom. Escutelo de coloração amarelo-dourado. Cada élitro com sete máculas: as quatro primeiras alongadas, lineares, longitudinais, de tamanho semelhante, atingindo pouco mais que a metade anterior do élitro, podendo ou não apresentar união. A primeira, próxima a sutura menor que a segunda; a segunda, mais larga e longa que a primeira; a terceira com a base sobre o calo umeral, pouco mais longa que a segunda, com a base formando um ângulo agudo em direção ao escutelo; a quarta, paralela ao bordo externo, com ápice afilado; quinta, sexta e sétima máculas na região apical do élitro: a quinta acolada à sutura elitral, formando 
com a do élitro oposto uma única mácula retangular; sexta mácula triangular com a base voltada para o ápice da segunda mácula; sétima mácula alongada, acompanhando o bordo externo do élitro.
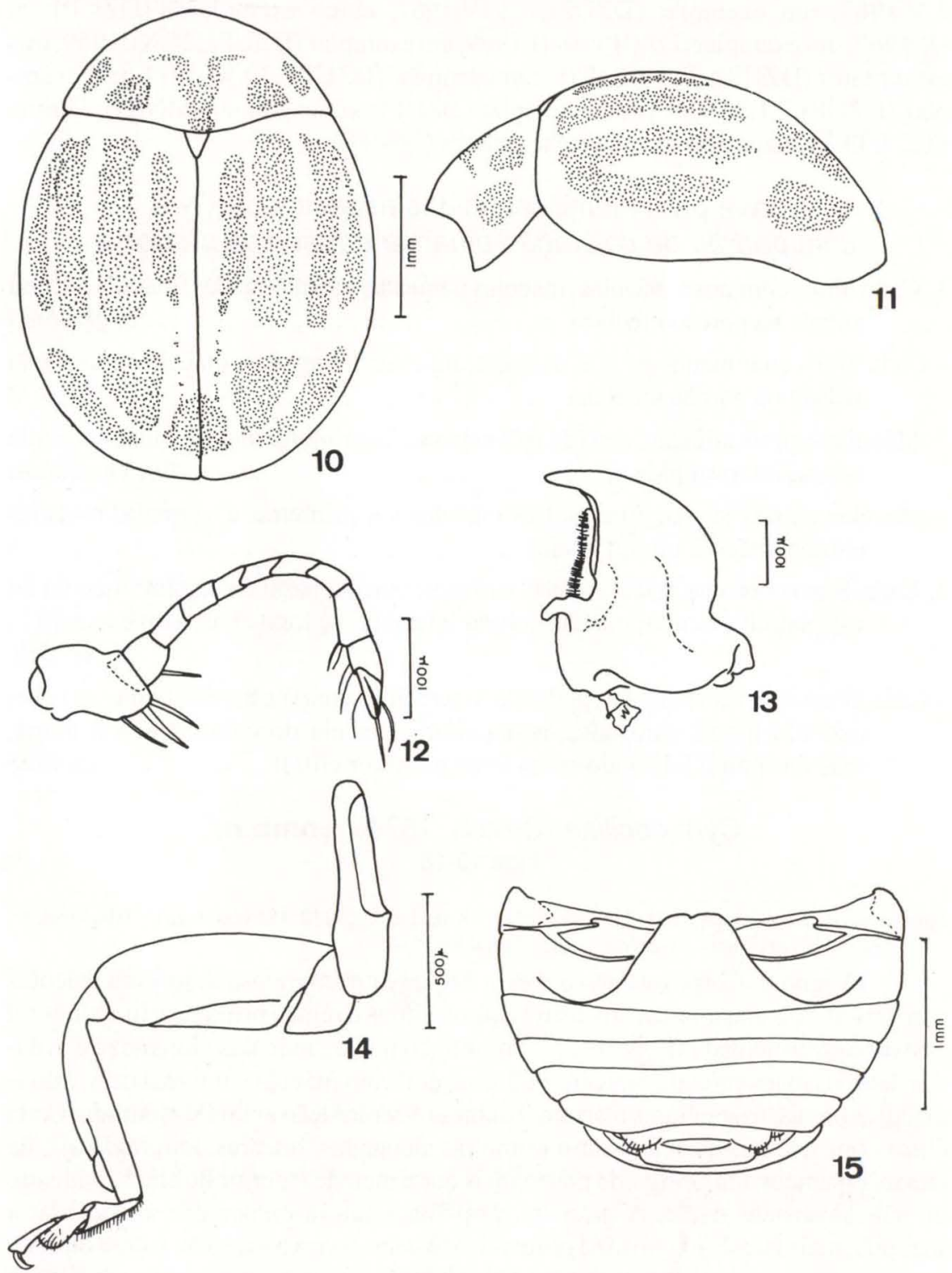

Figs 10-15. Cyra ceciliae. (10) Pronoto e élitros, vista dorsal; (11) pronoto e élitros vista lateral; (12) antena; (13) mandíbula; (14) perna anterior; (15) abdome. 


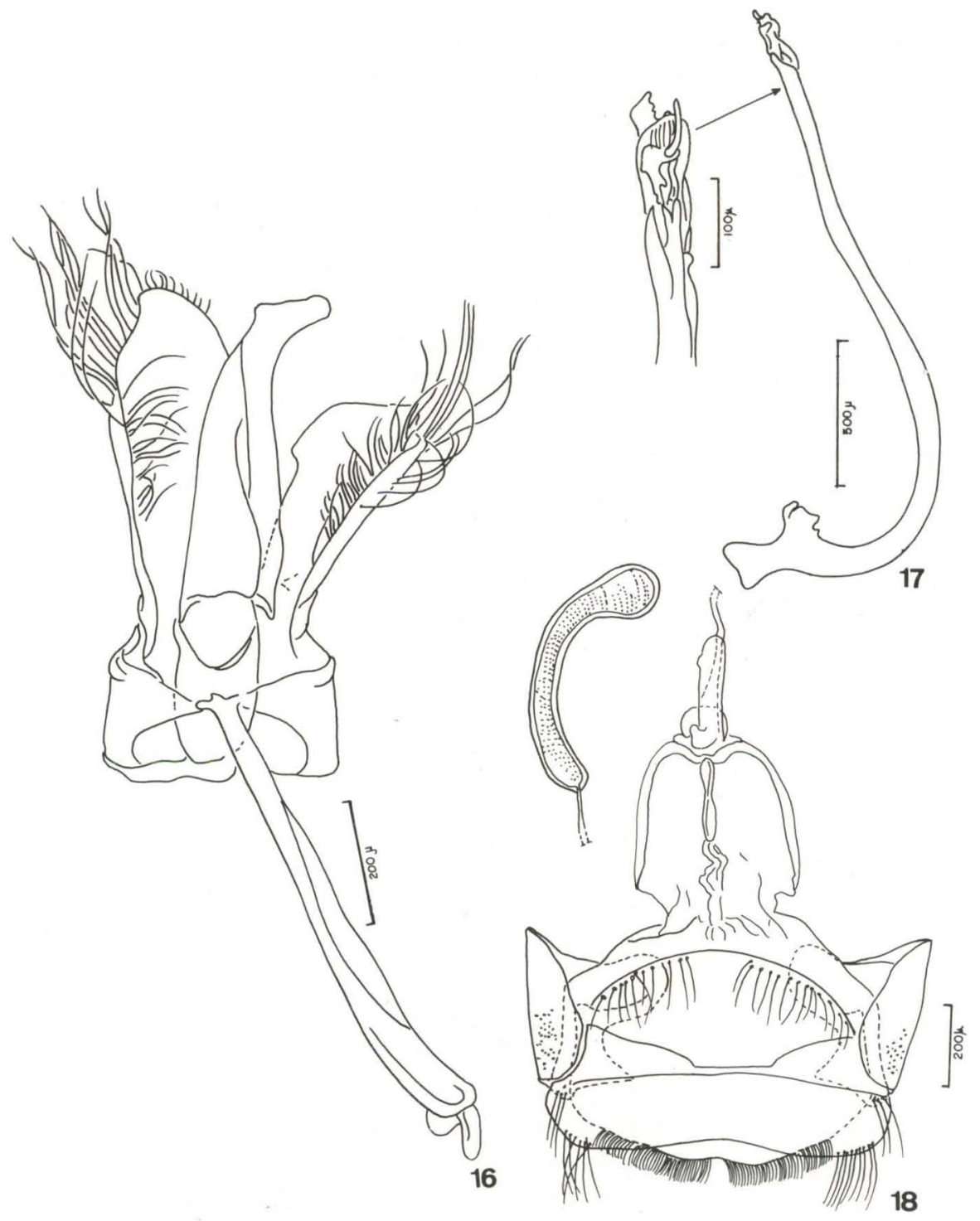

Figs 16-18. Cyra ceciliae. (16) tégmem; (17) sifão; (18) genitália da fêmea.

Medidas em milímetros. Comprimento 3,25-3,92. Largura 2,42-2,92.

Genitália. Machos: lobo médio assimétrico, de tamanho aproximadamente igual ao maior parâmero, base larga, ápice truncado, de lados arredondados, voltado para o menor parâmero; parâmeros foliáceos, muito largos, de bordos com cerdas longas, com comprimentos desiguais: um de comprimento igual ao do lobo médio e o outro com aproximadamente $2 / 3$ do lobo médio (Fig. 16). Sifão alongado, 
curvado; ápice modificado (Fig. 17). Fêmeas: placa genital larga, com discreto estilo; espermateca em arco, com corno arredondado e alargado, sem ramo; infundíbulo cilíndrico. Último esternito com densa franja de cerdas mais curtas que as dos estilos (Fig. 18).

Variações intraespecíficas. A mácula central do pronoto em forma de $\mathrm{V}$ pode ter as hastes expandidas lateralmente; as primeira e segunda máculas dos élitros podem estar unidas; a quarta mácula pode estar ligada à terceira na região do calo umeral.

Discussão taxonômica. Cyra ceciliae assemelha-se a C. hybridula por apresentar um maior número de máculas alongadas e afiladas nos élitros. Diferem entre sí pela genitália do macho que em $C$. ceciliae apresenta parâmeros de tamanhos diferentes e pela forma do ápice do lobo médio.

Material-tipo. O holótipo de Hyperaspis ceciliae, do Brasil, foi examinado e encontra-se depositado na UMZC.

Material examinado. BRASIL. Holótipo, um exemplar (UMZC); Rio de Janeiro: Represa Rio Grande, 20.V.1967, F.M. Oliveira leg., um exemplar (DZUP); São Paulo: Cantareira, XI.1939, Zellibor leg., um exemplar (MNRJ); Santa Catarina: Seara (Nova Teutônia), 30.VIII.1937, um exemplar (DZUP); 21.XII.1938, um exemplar (DZUP); 11-14.VIII.1939, três exemplares (DZUP); XI.1958, dois exemplares (DZUP); XI.1959, um exemplar (DZUP); I.1960, um exemplar (DZUP); III.1960, quatro exemplares (DZUP); X.1965, um exemplar (DZUP); IV.1966, seis exemplares (DZUP); V.1966, um exemplar (DZUP); IX.1966, três exemplares (DZUP); II.1968, um exemplar (DZUP); VI.1968, quatro exemplares (DZUP); V.1969, um exemplar (DZUP); XI.1969, um exemplar (DZUP); I.1974, quatro exemplares (DZUP); X.1974, F. Plaumann leg., um exemplar (DZUP); IX.?, um exemplar (MNRJ); 263/ FCC- 409, um exemplar (MNRJ); 671/ FCC- 911, um exemplar (MNRJ); 672/ FCC-912, F. Plaumann leg., um exemplar (MNRJ); Rio Grande do Sul: Porto Alegre (Vila Oliva), 12.VII.1964, um exemplar (MAPA).

\section{Cyra hybridula (Crotch, 1874), comb.n. \\ Figs 19-22}

Hyperaspis hybridula Crotch, 1874: 218 (descrição). - Korschefsky, 1932: 190 (catálogo). Blackwelder, 1945: 447 (catálogo). - Gordon, 1987: 27 (catálogo).

Diagnose. Corpo ovalar, convexo. Tegumento amarelo-pálido com manchas marrom-claras, no pronoto e élitros, e região próxima a linha sutural castanho-avermelhada (Fig. 19). Pronoto com sete máculas: três basais, as laterais triangulares e a central, menor, ovalada e longitudinal; quatro apicais, as duas laterais ovaladas, menores, longitudinais e de mesmo tamanho que a central basal, as duas apicais, em forma de triângulo com ápice voltado para o escutelo e margens externas arredondadas. Escutelo marrom-claro. Cada élitro com sete máculas: duas basais, a primeira pequena e cordiforme, a segunda sobre o calo umeral, triangular, com ápice prolongando-se para margem lateral; duas máculas paralelas à sutura, a anterior retangular, e a posterior, mais longa e com o ápice voltado para a margem lateral; uma mácula mediana a mais longa de todas, com ápice envolvido pela última mácula 

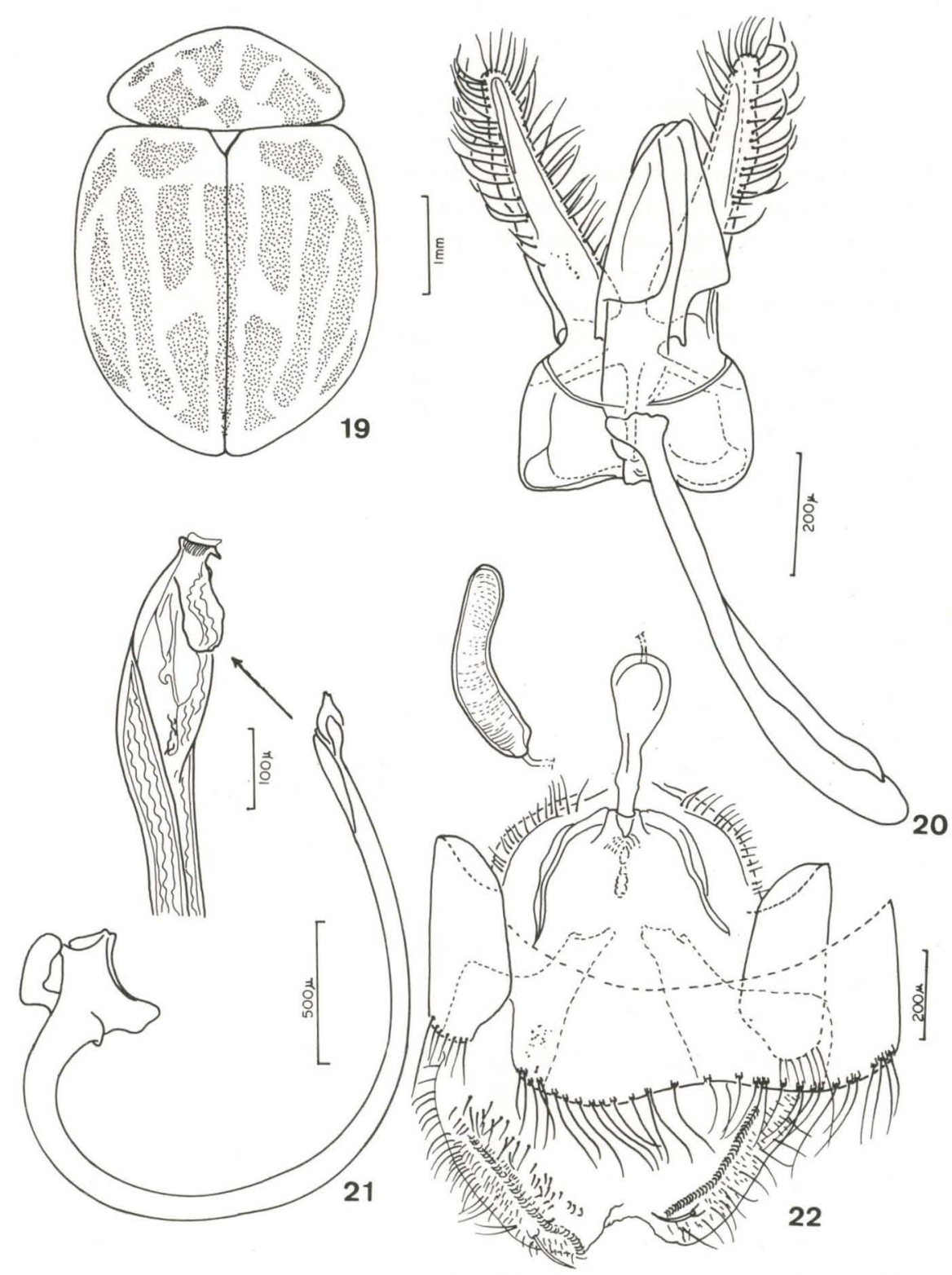

Figs 19-22. Cyra hybridula. (19) pronoto e élitros; (20) tégmem; (21) sifão; (22) genitália da fêmea. 
sutural; paralela a esta; sexta mácula alongada, de tamanho pouco menor, com ápice e base em pontas; sétima mácula afilada, paralela à margem lateral e abaixo da mácula do calo; uma mácula sutural, que se inicia na altura da base da terceira mácula, alarga-se até o ápice desta, deste ponto, forma uma faixa estreita até o final da linha sutural.

Medidas em milímetros. Comprimento 3,17-4,75. Largura 2,17-3,58.

Genitália. Machos: lobo médio assimétrico, menor que os parâmeros, base larga, ápice afilado levemente truncado; parâmeros foliáceos, relativamente estreitos, de bordos rodeados por cerdas longas, com comprimentos iguais (Fig. 20). Sifão alongado, curvado; ápice truncado e região pré-apical alargada, com área membranosa (Fig. 21). Fêmeas: placa genital larga, com discreto estilo; espermateca cilíndrica, curvada, com corno arredondado, pequeno ramo; infundíbulo presente. Último esternito com densa fileira de cerdas longas (Fig. 22).

Discussão taxonômica. Assemelha-se a C ceciliae pelo padrão de máculas, porém diferencia-se pelo ápice do lobo médio e parâmeros. $\mathrm{O}$ último esternito abdominal da fêmea em $C$. hybridula apresenta cerdas largas em forma de dentículos.

Material-tipo. O holótipo de Hyperaspis hybridula, de Nova Friburgo, Brasil, foi examinado e encontra-se depositado na UMZC.

Material examinado. BRAsIL, Rio de Janeiro: Holótipo, Nova Friburgo, um exemplar (UMZC); Paraná: Morretes, 20.X.1968, Pe. oure leg., um exemplar (DZUP); FCC-904, Pisarsky leg., um exemplar (MNRJ); Santa Catarina: Seara (Nova Teutônia), 5.X.1937, um exemplar (DZUP); 26.VIII.1938, um exemplar (DZUP); 5.XII.1938, um exemplar (DZUP); 10.VIII.1939, um exemplar (DZUP); IX.1956, um exemplar (DZUP); II.1960, quatro exemplares (DZUP); VI.1960, dois exemplares (DZUP); X.1961, um exemplar (DZUP); IX.1962, três exemplares (DZUP); X.1962, seis exemplares (DZUP); II.1966, um exemplar (DZUP); IV.1966, (DZUP); IX.1966, um exemplar(DZUP); XI.1966, um exemplar (DZUP); X.1967, cinco exemplares (DZUP);VI.1968, um exemplar (DZUP); VII.1968, cinco exemplares (DZUP); XI.1968, quatro exemplares (DZUP); I.1974, um exemplar (DZUP); V.1974, 22 exemplares (DZUP); X.1980, F. Plaumann leg., quatro exemplares (DZUP); Cerro Negro (?), XII.1962, F. Plaumann leg., um exemplar (DZUP).

\section{Cyra fuscomaculata (Mulsant, 1850), comb.n. Figs 23-26}

Cleothera fuscomaculata Mulsant, 1850: 569 (descrição).

Hyperaspis fuscomaculata: Crotch, 1874: 218 (sistemática). - Korschefsky, 1932: 189 (catálogo). Blackwelder, 1945: 447 (catálogo). - Gordon, 1987: 27 (catálogo).

Diagnose. Corpo ovalar, convexo. Tegumento amarelo-pálido com máculas marrom-pinhão, no pronoto e élitros, e região próxima a linha sutural castanho-avermelhada (Fig. 23). Pronoto com sete máculas: três basais, a central menor e triangular, as laterais, maiores e trapezoidais; duas apicais, triangulares, centrais, com o ápice voltado para o escutelo e duas ovalares, laterais, oblíquas, menores que 

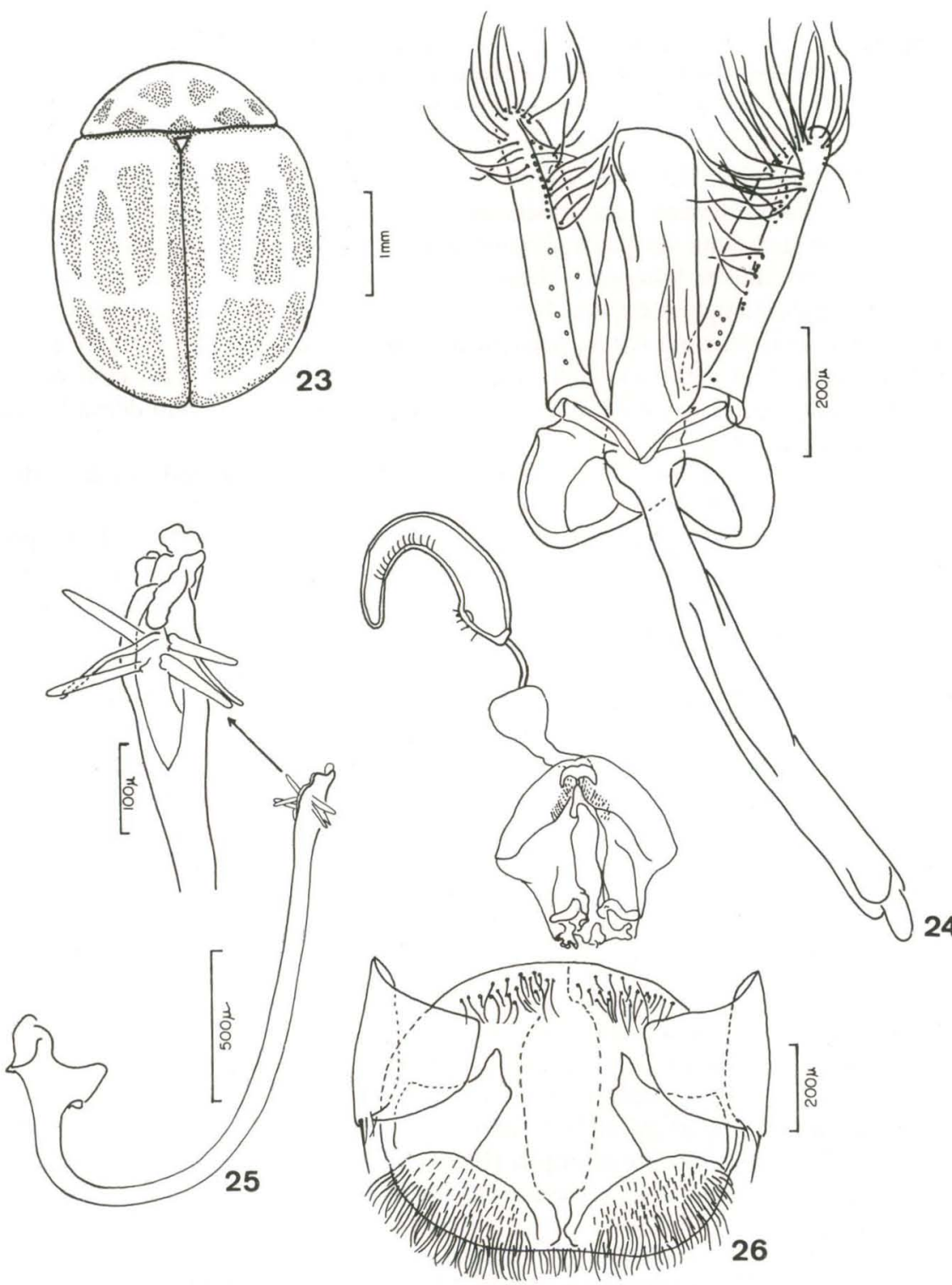

Figs 23-26. Cyra fuscomaculata. (23) pronoto e élitros; (24) tégmem; (25) sifão; (26) genitália da fêmea.

as demais. Escutelo marrom. Cada élitro com cinco máculas: três basais, alongadas; a primeira próxima da sutura, retangular, com a base mais larga que o ápice; a segunda, central, um pouco menor, com a base mais afilada que o ápice; a terceira sobre o calo umeral, pouco mais larga que as demais; duas máculas apicais, uma 
próxima da sutura, triangular, maior; e outra lateral, alongada. Sutura com uma faixa desde o escutelo, um pouco mais espessada na região da primeira mácula basal, estreitada em direção ao ápice, de onde continua para a margem lateral, até o ápice da quinta mácula, de forma evanescente.

Medidas em milímetros. Comprimento 3,08-3,67. Largura 2,50-2,75.

Genitália. Machos: lobo médio assimétrico, menor que os parâmeros, base larga, ápice truncado, de lados arredondados, com ápice voltado para um dos pârameros; parâmeros foliáceos, relativamente estreitos, côncavos, de bordos afilados, com cerdas longas internas e marginais (Fig. 24). Sifão alongado, curvado; com seis espículas laterais na região pré-apical membranosa (Fig. 25). Fêmeas: placa genital larga, com estilo evidente; espermateca cilíndrica, em arco, com corno afilado e ramo pequeno; infundíbulo presente. Último esternito com densa fileira de cerdas longas (Fig. 26).

Variação intraespecífica. As máculas centrais do pronoto podem estar todas mais ou menos fundidas.

Material-tipo. O holótipo de Hyperaspis fuscomaculata de Nova Friburgo, Brasil, não examinado, pertence a coleção Dejean e GoRDON (1987) indicou, com dúvida, que deva estar no Muséum Histoire Naturelle, Lyon ou no Muséum National d'Histoire Naturelle, Paris, França.

Material examinado. BRASIL: ?, um exemplar (UMZC); Minas Gerais: Mar de Espanha, 27-28.II.1962, um exemplar (MZSP); 1-2.III.1962, J. Bechyné leg., dois exemplares (MZSP); Santa Barbara (Serra do Caraça), 23-25.XI.1960, Araújo \& Martins leg., um exemplar (MZSP); XI.1961, Kloss, Lenko, Martins \& Silva leg., um exemplar (MZSP); XII.1972, Exp. Mus. Zool, dois exemplares (MZSP); Lagoa Santa, Reinh leg., dois exemplares (MNRJ); Rio de Janeiro: Rio de Janeiro (Floresta da Tijuca), I.1961, dois exemplares (DZUP); II.1961, C.A. Campos Seabra leg., um exemplar (DZUP); II.1957, M. Alvarenga leg., um exemplar (DZUP); Rio de Janeiro (Represa Rio Grande), 20.X.1960, F.M. Oliveira leg., um exemplar (DZUP); 3.II.1967, F.M. Oliveira leg., um exemplar (DZUP); Nova Friburgo, um exemplar(UMZC); Petrópolis, 5-7.III.1962, J. Bechyné, um exemplar(DZUP); São Paulo: São Paulo (Cantareira), 17.II.1960, um exemplar (MZSP); 14.IX.1962, um exemplar (MZSP); 19.XI.1967, J. Halik leg., um exemplar (MZSP); Itú (Fazenda Pau D'Alho), XII.1958, Martins leg., um exemplar (MZSP); Batêa (?), 2.XI.1940, Lane leg., um exemplar (MNRJ); Barueri, 21.XI.1955, dois exemplares (MNRJ); VII.1955, K. Lenko leg., um exemplar (MNRJ); Campinas, um exemplar (MNRJ); sem procedência, Melo leg., um exemplar (MNRJ). Sem procedência, três exemplares (UMZC).

\section{Cyra glyphica (Mulsant, 1850), comb.n. Figs $27-30$}

Cleothera glyphica Mulsant,1850: 585 (descrição).

Hyperaspis glyphica: Crotch, 1874: 220 (sistemática). - Korschefsky, 1932: 189 (catálogo). Blackwelder, 1945: 447 (catálogo). - Gordon, 1987: 27 (catálogo).

Diagnose. Corpo ovalar, convexo. Tegumento amarelo-pálido com máculas marrom-escuras à marrom-pinhão, no pronoto e élitros, e região próxima a linha sutural castanho-avermelhada (Fig. 27). Pronoto com sete máculas: três basais, a 


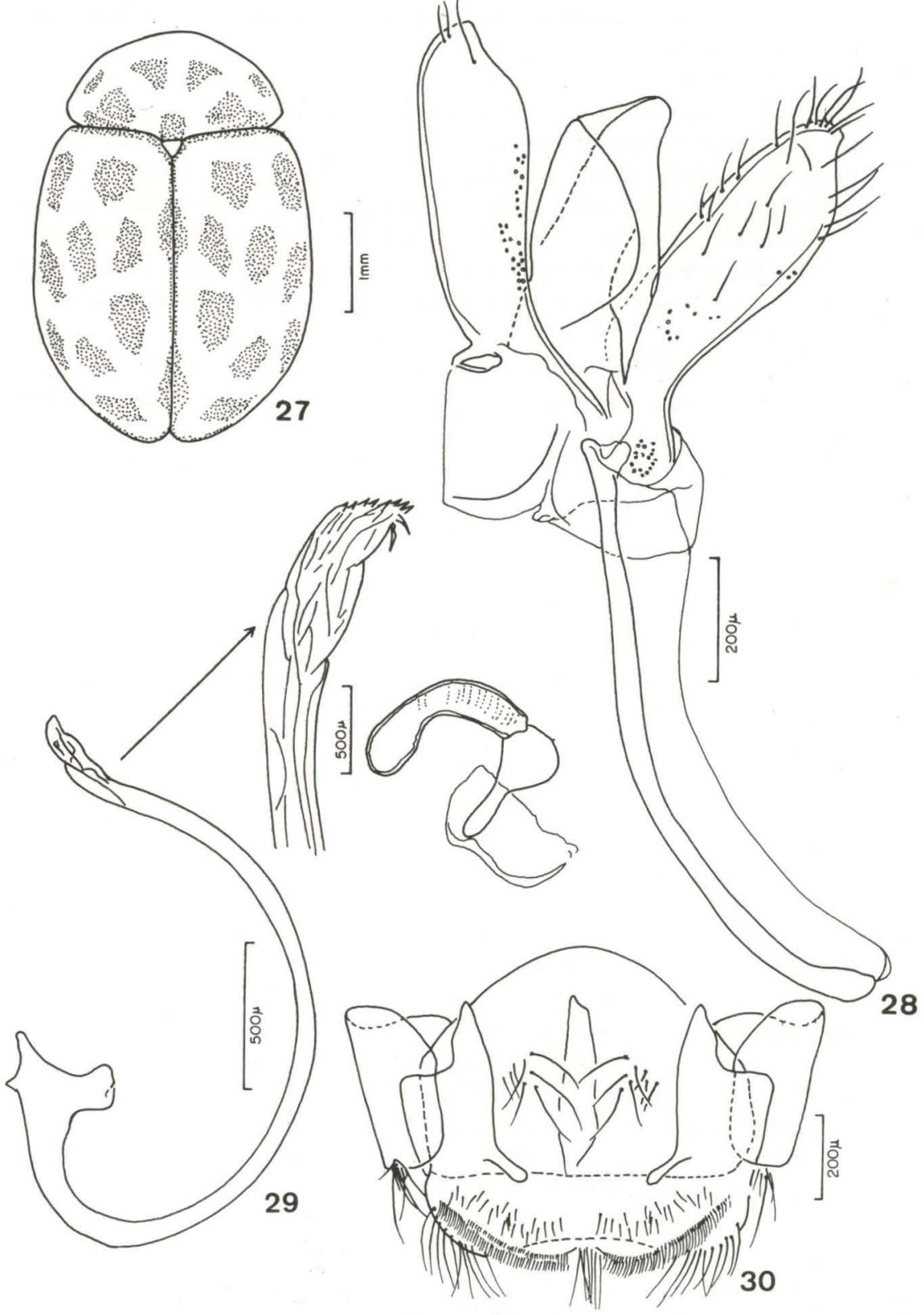

Figs 27-30. Cyra glyphica. (27) pronoto e élitros; (28) tégmem; (29) sifão; (30) genitália da fêmea. 
central, menor e trapezoidal; as laterais, maiores; duas apicais, triangulares, centrais, com o ápice voltado para o escutelo, de margens laterais externas arredondadas; e duas ovalares, laterais, oblíquas, menores que as demais. Escutelo negro. Cada élitro com nove máculas: duas basais; a primeira próxima a sutura, subquadrangular; a segunda sobre o calo umeral ovalada; três máculas em fileira transversal; a terceira próxima ao primeiro alargamento da faixa sutural, ovalada; a quarta, central, subretangular; a quinta, lateral, subtriangular; três máculas, em fileira transversal, arcada em direção ao ápice elitral; a sexta mácula, próxima a linha sutural, triangular com o ápice voltado para baixo; a sétima, central e ovalada de contorno sinuoso; a oitava, lateral subtriangular alongada e a nona, apical, subtriangular. Linha sutural em faixa estreita, alargando-se próxima a terceira mácula e novamente entre as sexta e nona máculas.

Medidas em milímetros. Comprimento 2,58-3,92. Largura 2,00-3,17.

Genitália. Machos: lobo médio assimétrico, menor que os parâmeros, base larga, ápice truncado, de lados arredondados, voltado para um dos parâmeros; parâmeros foliáceos, muito largos, com ápices afilados, de bordos rodeados por cerdas relativamente curtas e esparsas e poucas cerdas internamente (Fig. 28). Sifão alongado, curvado, com ápice modificado em pontas (Fig. 29). Fêmeas: placa genital larga, com estilo evidente; espermateca cilíndrica, pouco curvada, com corno arredondado, com ramo muito pequeno; infundíbulo presente. Último esternito com densa fileira de cerdas curtas e no centro com tufo de longas cerdas (Fig. 30).

Variações intraespecíficas. As máculas basais do pronoto podem estar mais ou menos unidas na base; a quarta mácula pode estar unida à sétima que pode ser ovalada e oblíqua.

Discussão taxonômica. Esta espécie isola-se das demais principalmente pelo padrão elitral que apresenta máculas pequenas e não distribuídas em faixas alongadas. Diferencia-se também por possuirem genitália do macho com parâmeros largos com ápice afilado e cerdas curtas e esparsas.

Material-tipo. O holótipo de Hyperaspis glyphica, do Brasil, não foi examinado, e GORDON (1987) indicou, com dúvida, que deva estar no Muséum National d'Histoire Naturelle, Paris, França.

Material examinado. BRASIL: ?, um exemplar (UMZC); Pará: Mocajuba (Mangabeira), VIII.1953, O.Rego leg., um exemplar, Coleção Campos Seabra (MNRJ); Jacareacanga, X.1959, M.Alvarenga leg., dois exemplares (DZUP); Mato Grosso: Chapada Guimarães, XI.1983, Exc. Dep. Zool. UFPR, Polonoroeste, um exemplar (DZUP); Minas Gerais: Camanducaia (Vila Monte Verde), 1819.IX.1962, três exemplares (MZSP); 7.XII.1964, um exemplar (MZSP); 14.III.1966, dois exemplares (MZSP); 21.XI.1966, dois exemplares (MZSP); 9.XII.1966, um exemplar (MZSP); 4.V.1967, dois exemplares (MZSP); 23.III.1969, um exemplar (MZSP); 23.III.1969, um exemplar (MZSP); 12.XI.1969, um exemplar (MZSP); 10.XII.1969, J. Halik leg., um exemplar (MZSP); Lagoa Santa, Reinh leg., um exemplar (MNRJ); Rio de Janeiro: Nova Friburgo, um exemplar (UMZC); Teresópolis, 17.XI.1955, D. Zajciw leg., três exemplares (MNRJ); São José Barreiros (S.Bocaína), XI.1967, oito exemplares, ex-coleção M. Alvarenga(DZUP); XI.1968, Alvarenga \& Seabraleg., dois exemplares, ex-coleção 
M. Alvarenga (DZUP); São Paulo: São Paulo (Cantareira), XI.1939, Zellibor leg., um exemplar (MNRJ); 24.XII.1939, J. Halik leg., um exemplar (DZUP); São Bernardo do Campo, X.1960, um exemplar (DZUP); 18.X.1961, J. Halik leg., dois exemplares (DZUP); XI.1959, W. Bokermann leg., cinco exemplares (DZUP); 26.XII.1959, dois exemplares (DZUP); Campos do Jordão, XII.1963, Seabra \& Oliveira leg., um exemplar, ex-coleção M. Alvarenga (DZUP); Salesópolis (Estação Biológica Boraceia), 14-18.XI.1973, Exp. Mus. Zool., um exemplar (DZUP); 1.XII.1967, J. Oliveira Santos leg., um exemplar (DZUP); Campo de Jordão, um exemplar (MZSP); Paraná: Ponta Grossa (Pedreira), X.1946, um exemplar, Coleção F. Justus (DZUP); Santa Catarina: São Bento do Sul (Rio Vermelho), VI.1958, Dirings leg., dois exemplares (DZUP); Xanxeré, XI.1962, F. Plaumann leg., um exemplar (DZUP); FCC- 825, três exemplares (MNRJ); sem procedência, quatro exemplares (MNRJ); Rio Grande do Sul (Canela) (?), IV.1966, um exemplar (MAPA); sem procedência, um exemplar (UMZC).

\section{REFERÊNCIAS BIBLIOGRÁFICAS}

BLACKWELDER, R.E. 1945. Checklist of the Coleopterous Insects of Mexico, Central America, the West Indies, and South America. U.S. Natn. Mus. Bull. 185 (3): 343-550.

CHAPIN, E.A. 1966. A new species of myrmecophilous Coccinellidae with notes on other Hyperaspini (Coleoptera). Psyche 73: 278-283.

CROTCH, G.R. 1874. A revision of the coleopterous family Coccinellidae. London, E.W. Janson, $311 \mathrm{p}$.

Duverger, C. 1989. Contribuition à l'étude des Hyperaspinae. $1^{\text {ère }}$ note (Coleoptera, Coccinellidae). Bull. Soc. Linn. Bordeaux 17 (3): 143-157.

GoRDon, R.D. 1985. The Coccinellidae (Coleoptera) of America North of Mexico.

Jour. N.Y. Ent. Soc. 93 (1): .1-912. 1987. A catalogue of the Crotch collection of Coccinellidae (Coleoptera).

Oc. Pap. Syst. Ent. 3: 1-46.

KoRSCHEFSKY, R. 1932. Coleopterorum Catalogus, 118. Coccinellidae I. Berlin,

W. Junk, p.1-224.

Mulsant, M.E. 1850. Species de Coléoptères trimères sécuripalpes. Ann. Sci.

Phys. Nat. Lyon. 2: 1-1104. 1853. Supplément Spécies des Coléoptères Sécuripalpes. Ann. Soc. Linn.

Lyon. 2 (1): 129-334. 